\title{
Bullous lung disease in association with an isolated giant plexiform neuroma: A case report and brief review of pulmonary involvement in neurofibromatosis type 1
}

\author{
M S Shongwe, MB ChB; M J Mpe, MB ChB, FCP (SA), Cert Pulm (SA) \\ Department of Medicine, Division of Pulmonology, Sefako-Makgatho Health Sciences University, Pretoria, South Africa
}

Corresponding author: M J Mpe (oupa.mpe@gmail.com)

Neurofibromatosis is common. It can be accompanied by abnormalities related to the thorax. These vary in severity and can be lifethreatening. We present a case of plexiform neuroma with associated extensive bullous lung disease.

Keywords. isolated plexiform neuroma; bullous lung disease.

Afr J Thoracic Crit Care Med 2021;27(4): 168-170. https://doi.org/10.7196/AJTCCM.2021.v27i4.128

\section{Case}

A 41-year-old male patient with a large plexiform neuroma involving the right arm was referred to our respiratory clinic with a long-standing dry cough and progressively worsening and severe shortness of breath. The symptoms had been ongoing for approximately 9 years, and he was now breathless at rest. He had no associated orthopneoa, paroxysmal nocturnal dyspnoea or ankle swelling. There was no previous history of cardiac disease. He is a life-time non-smoker and has no history of substance abuse. He had no environmental or occupational exposures of note. There was family history of emphysema.

Clinically, he was breathless at rest and centrally cyanotic. He was in overt right heart failure. There was no digital clubbing or lymphadenopathy. His chest was hyperinflated and there was clinical pulmonary hypertension. The plexiform neuroma involving his right arm was evident. Café au lait macules were conspicuously absent and there were no other nodules on the body.

Pulmonary function tests were not performed as the patient was seen amid the severe acute respiratory syndrome-coronavirus-2 (SARS-CoV-2) pandemic. His alpha-1 antitrypsin level was normal, and he was non-reactive for the retroviral disease. His arterial blood gas showed severe hypoxaemia with carbon dioxide retention (partial pressure of $\mathrm{O}_{2}\left(\mathrm{PaO}_{2}\right)=5.44 \mathrm{kPa} ; \mathrm{PaCO}_{2}=7.17 \mathrm{kPa}$; $\mathrm{pH}=7.357$; and bicarbonate ion $=30.1 \mathrm{mmol} / \mathrm{L})$.

A computed tomography (CT) scan of the chest showed scattered bullous changes and prominent pulmonary arteries (Figs 1 and 2). He was treated for right heart failure and arranged for long-term oxygen therapy.

\section{Discussion}

Neurofibromatosis type 1 (NF1) affects $\sim 1$ in 2000 - 3000 live births. ${ }^{[1]}$ Approximately half of the cases are sporadic, and the other half are familial with autosomal dominant inheritance. Penetrance is complete but the clinical manifestations and disease severity are variable, even within the same family. ${ }^{[2]}$

Plexiform neuromas are among the most common and debilitating complications of NF1. They occur in about $30 \%$ of patients with NF1, and they have been described to occur in isolation. ${ }^{[3,4]}$ They are benign, diffuse tumours, originating from nerve cell sheaths and can involve multiple fascicles. They are subject to malignant transformation.

The first description of pulmonary involvement in patients with NF1 was over half a century ago. ${ }^{[5]}$ Since then, there have been several case series and case reports worldwide. We are aware of only one case report in South Africa that was described $>30$ years ago, and it is believed that there are likely to be more. ${ }^{[6]}$

Thoracic involvement can be severe and life threatening. ${ }^{[7,8]}$ Virtually all components of the thorax can be involved. The abnormalities have

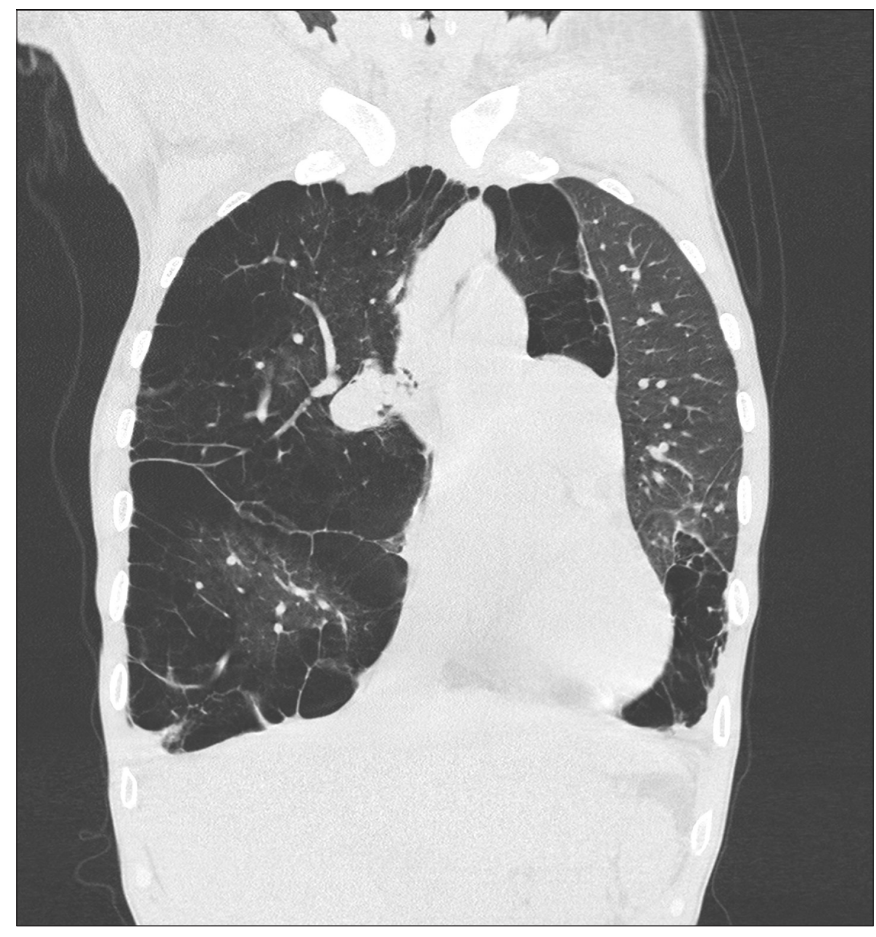

Fig. 1. Coronal cut showing extensive bullous changes. 


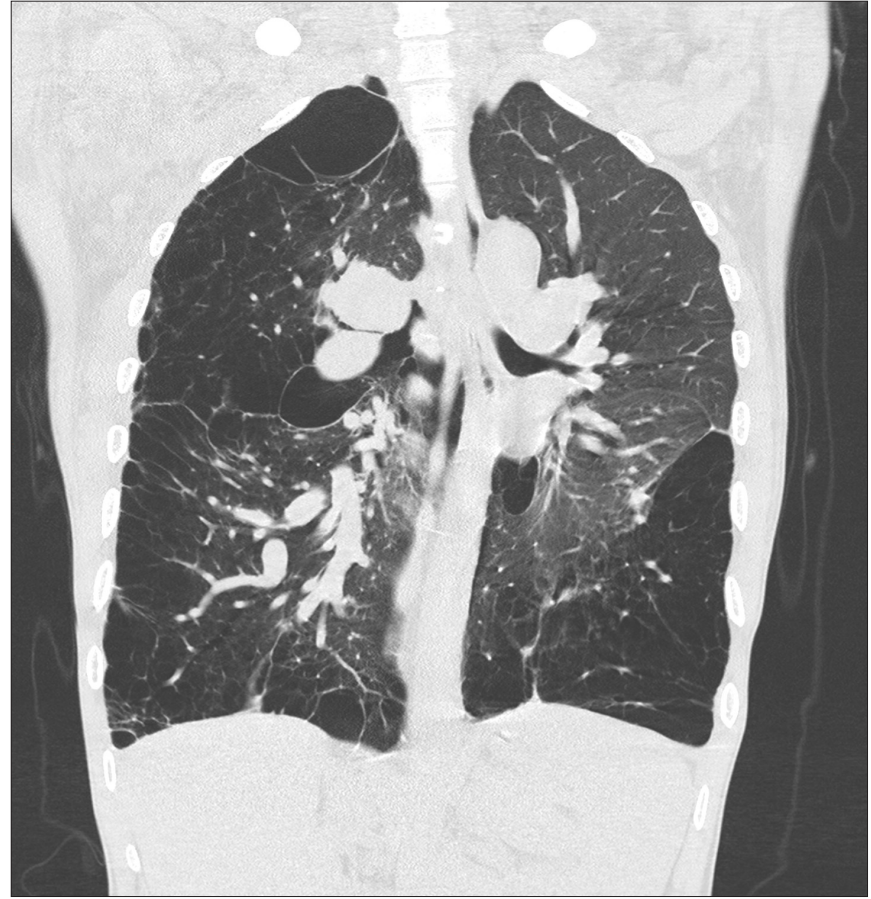

Fig. 2. Coronal chest computed tomography cut showing marked dilatation of pulmonary arteries.

been clearly demonstrated on high-resolution chest CAT scans, and in some cases, surgical lung biopsy. ${ }^{[9,10]}$

Neurofibromas can be found in the skin and subcutaneous tissue of the chest wall. ${ }^{[9]}$ Defects in the development of the thoracic skeleton lead to varying degrees of kypho-scoliosis, vertebral abnormalities, and characteristic rib deformities. ${ }^{[11]}$

Neurofibromata arising from the pleuro-parenchymal nerves, as well as endobronchial neurofibromata have been described, although these are rare. ${ }^{[12]}$ An association between NF1 and lung cancer has been proposed following reports of a few scattered cases of NF1 and lung cancer. ${ }^{[13,14]}$ Additional studies with larger cohorts are necessary to firmly establish NF1 as a risk factor for lung cancer

Diffuse parenchymal lung disease occurs in $\sim 10-20 \%$ of individuals. ${ }^{[13]}$ Pathologically, interstitial fibrosis with lymphoplasmocytic inflammation consistent with nonspecific interstitial pneumonitis has been described. ${ }^{[10,13]}$ The interstitial reticulations predominate at the lung bases. The pathogenesis of the fibrotic process is thought to be secondary to the mesenchymal defect that leads to primary deposition of collagen. ${ }^{[10]}$ Elevated serum levels of nerve growth factor have also been described. This factor is known to directly stimulate fibroblasts differentiation into more pro-fibrogenic myofibroblasts. ${ }^{[15]}$ Other interstitial/parenchymal findings have included micro-nodules, ground-glass opacities, cysts, emphysematous bullae, and honeycombing. ${ }^{[10]}$ The cysts have tended to predominate in the upper lung fields in the central and subpleural locations.

Mediastinal lesions in the form of neurofibromata, malignant peripheral nerve tumours and lateral meningocoeles have been observed. ${ }^{[10]}$

Pulmonary arterial hypertension is a rare but serious complication of NF1 and carries a poor prognosis. ${ }^{[8]}$ Its pathogenesis is not clearly understood and likely multifactorial. While it may be secondary to the architectural distortion and hypoxia resulting from the underlying lung disease, pulmonary vasculopathy associated with NF1 has also been postulated. ${ }^{[16]} \mathrm{NF} 1$ has a well-known association with systemic vasculopathy, affecting multiple vessels. In addition, neurofibrin, an NF1-encoded protein, is expressed in endothelial and smooth-muscle cells. It regulates cell growth and proliferation, and its deficiency is expected to interfere with the response of these vessels to growth suppressor signals. ${ }^{[16]}$

The general care of adult patients with NF1 is summed up in guideline documents. ${ }^{[17]}$ Targeted treatment of the specific thoracic complication is largely the same as pathologically similar pulmonary problems in the general population. Patient education is important in relation to the use of tobacco products and timely report of respiratory symptoms. Routine radiological screening for the chest manifestations is not recommended by most NF1 guidelines. ${ }^{[17]}$ However, it remains advisable for patients to be offered regular clinic visits so complications can be detected early and appropriate treatment, where available, initiated timeously.

Declaration. None.

Acknowledgements. None.

Author contributions. Equal contributions.

Funding. None.

Conflicts of interest. None.

1. Williams VC, Lucas J, Babcock MA, Gutmann DH, et al. Neurofibromatosis type 1 revisited. Review Paeds 2009;123(1):124-133. https://doi.org/10.1542/peds.20073204

2. Reviron-Rabec L, Girerd B, Seferian A, et al. Pulmonary complications of type 1 neurofibromatosis. Review Rev Mal Respir 2016;33(6):460-473. https://doi. org/10.1016/j.rmr.2014.09.010

3. Mishara PK, Dwivedi R, Shrivastava DC, Gaur SC. Isolated plexiform neuroma of arm with unusual presentation - a rare case report. J Clin Diagn Res 2015;9(1):RD03RDO4. https://doi.org/10.7860\%2FJCDR\%2F2015\%2F10530.5407

4. Stefano PC, Apa NS, Lanoel AM, Maria JS. Isolated plexiform neuroma mimicking a vascular lesion. An Bras Dermatol 2016;91(2):240242. https://doi.org/10.1590/ abd1806-4841.20164300

5. Davies PDB. Diffuse pulmonary involvement in von Recklinghausen's disease: A new syndrome. Thorax 1963;18:198.

6. Hardcastle SW, Hendricks ML. Neurofibromatosis (von Recklinghausen's disease) - an unusual cause of parenchymal lung disease. S Afr Med J 1984;60:959-960.

7. Negreira KS, Lichtenberger JP, Allais B, et al. Subclavian artery branch pseudoaneurysm rupture with massive hemothorax in a patient with neurofibromatosis type 1. Chest 2020;157(4):e103-e105. https://doi.org/10.1016/j.chest.2019.11.001

8. Rojas M, Mubarik A, Henderson E, et al. Pulmonary arterial hypertension: A rare yet fatal complication of neurofibromatosis type 1. Resp Med 2019:100832. https:// doi.org/10.1016\%2Fj.rmcr.2019.100832

9. Ueda K, Honda O, Satoh Y, et al. Computed tomography (CT) findings in 88 neurofibromatosis 1 (NF1) patients: Prevalence rates and correlations of thoracic findings. Eur J Rad 2015;84(6):1191-1195. https://doi.org/10.1016/j. ejrad.2015.02.024

10. Zamora AC, Collard HR, Wolters PJ, et al. Neurofibromatosis-associated lung disease: A case series and literature review. Eur Respir J 2007;29:210-214. https:// doi.org/10.1183/09031936.06.00044006

11. Semionov A, Kosiuk J, Ajlan A, Discepola F. Imaging of thoracic wall abnormalities. Korean J Radiol 2019;20(10):1441-1453. https://doi.org/10.3348\%2Fkjr.2019.0181

12. Boland JM, Colby TV, Folpe AL. Intrathoracic peripheral nerve sheath tumors a clinicopathological study of 75 cases. Hum Pathol 2015;46:419-425. https://doi. org/10.1016/j.humpath.2014.11.017

13. Alves Júnior SF, Zanetti G, Alves de Melo AS, et al. Neurofibromatosis type 1: Stateof-the-art review with emphasis on pulmonary involvement. Review Respir Med 2019;149:9-15. https://doi.org/10.1016/j.rmed.2019.01.002 
14. Oikonomou A, Mikroulis D, Mintzopoulou P, et al. Lung cancer associated with neurofibromatosis type I. Case Rep Radiology 2013;2013:869793. https://doi. org/10.1155\%2F $2013 \% 2 \mathrm{~F} 869793$

15. Fabricant RN, Todaro GJ. Increased serum levels of nerve growth factor in von Recklinghausen's disease. Arch Neurol 1981;38(7):401-405. https://doi.org/10.1001/ archneur.1981.00510070035003

16. Jutant E, Girerd B, Aïs X, et al. Pulmonary hypertension associated with neurofibromatosis type 1. Eur Respir Rev 2018;27:180053. https://doi.org/10.1183/16000617.0053-2018
17. Stewart DR, Korf BR, Nathanson KL, Stevenson DA. Care of adults with neurofibromatosis type 1: A clinical practice resource of the American College of Medical Genetics and Genomics (ACMG). Genet Med 2018;20(7):671-682. https:// doi.org/10.1038/gim.2018.28

Accepted 27 September 2021.
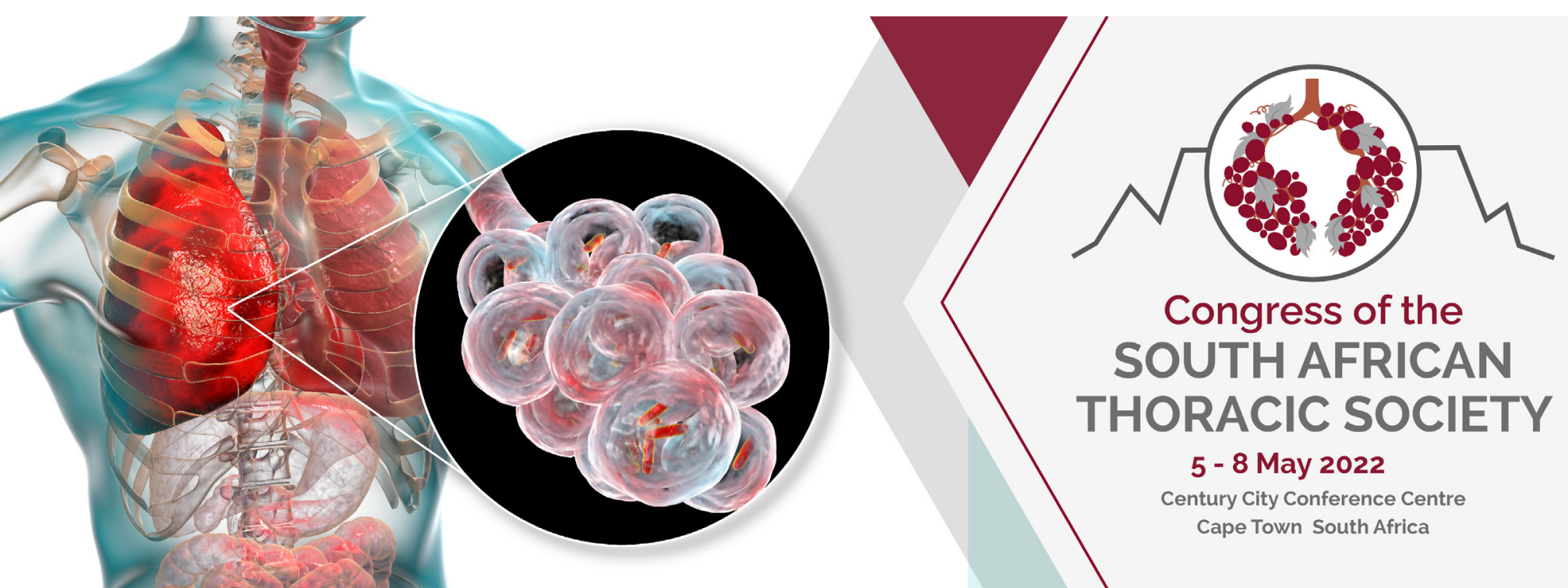

5 - 8 May 2022

Century City Conference Centre Cape Town South Africa 